\title{
Jhuma Sadhukhan, Kok Siew Ng and Elias Martinez Hernandez (Eds): Biorefineries and Chemical Processes-Design, Integration and Sustainability Analysis
}

\author{
Ken Jones
}

(C) Springer-Verlag Berlin Heidelberg 2015

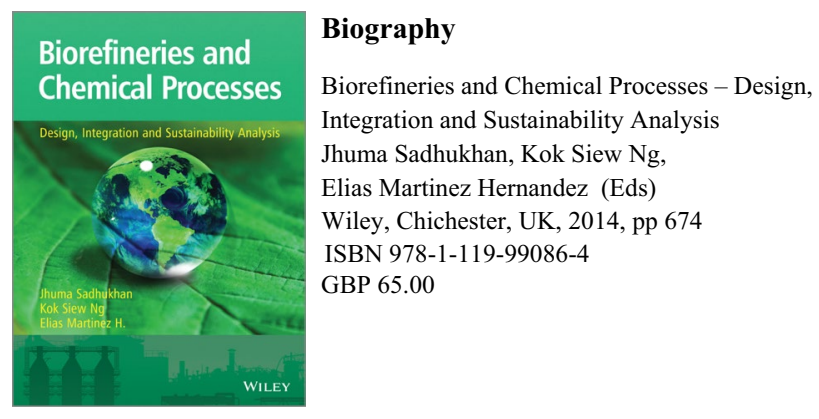

The concept of the "biorefinery" is not new; it was created almost 90 years ago by Fischer and Tropsch at the Max Plank Institute where low-grade brown coal was converted into high quality liquid fuels. Although a major technical breakthrough, price competition from cheaper crude oil resources condemned the technology to a minor role until Nazi Germany expanded the process to become its principal source of automotive and aviation fuels in the Second World War. The baton was later seized by South Africa when oil embargoes were applied as a result of its apartheid policy. SASOL, its state company, significantly scaled up and developed the process further. Today, it is a successful manufacturer of a very wide range of high quality liquid fuels with the ability to utilize a considerable range of carbonaceous feed stocks (see Chapter 14).

The last few decades have coupled the ever-present fear of crude oil shortages and price manipulation (ironic with the current drop in crude oil prices) with global warming, the primary cause of which is claimed to be excessive $\mathrm{CO}_{2}$ emissions. The European Union in particular, has reacted

K. Jones $(\square)$

Knutsford, Cheshire, UK

e-mail: chromatographia@springer.com by introducing massive subsidies to support the replacement of fossil fuels by biomass feedstocks. These include dedicated energy crops, agricultural wastes, algae and aquatic plants, wood and wood residues, animal wastes, wastes from food and from chemicals and materials. All of these are claimed to be "carbon neutral" but one major consideration is never emphasized-although all biomass feedstocks can produce energy and many can be recycled into useful products, the equation is not complete-the energy available from a unit weight of biomass is always very much less than the same unit weight of fossil fuel. To create economic parity requires huge subsidies. When new processes are presented as breakthrough technology, subsidies are not included and the real cost of the product is then inevitably disguised.

This book is designed as an advanced text for final year and post graduate chemical engineers as well as for the teaching staff. It deals with the specialized subject matter thoroughly with good explanations of the chemistries involved and emphasizes where conventional chemical engineering principles differ from those needed to design biorefinery plant. Admirably, an "economic analysis" chapter is provided and includes the standard discounted cash flow method for evaluating the ongoing financial viability of any production unit. It does not, however, state where and how the inevitable subsidies should be applied; in the R\&D costs, plant and offset construction costs, operating costs, inflated product cost or to all?

Environmental pressures are the current driver of biorefineries rather than war, sanctions or shortage of crude oil. If crude oil prices drop, subsidies need to increase, forcing governments to seek alternative more cost-competitive routes to achieve the same objective. 